\section{MUCORMYCOSIS UBIQUITOUS FUNGUS THRIVING IN IMIMUNOCOIMPROIMISED COVID PATIENT IN PATNA}

KEY WORDS:COVID-19, mucormycosis, diabetes, corticost eroids

\section{Dr.Manish Ranjan*}

Dr.Vineet Sinha

Dr.Neha Giri Dr. Abhisek Kishore Dayal Dr. Surbhi

\section{Dr. Amit Kumar}

Post Graduate Resident, Department of ENT, Patna Medical College, Patna. *Corresponding Author

Associate Professor, And Head of Department ENT, Patna Medical College, Patna

Post Graduate Resident, Department of Radiology, Patna Medical College, patna

Post Graduate Resident, Department of ENT, Patna Medical College, patna

Senior Resident, Department of ENT, Patna Medical College, Patna

Assistant Professor, Department of ENT, Patna Medical College, Patna

OBJECTIVE. To study various predisposition for sudden upsurge in mucormycosis in second wave of COVID

To study pattern of involvement and spread of disease and to correlate clinicoradiologically

METHOD: A prospective observational study was conducted at a tertiary care centre over 2months, involving all patients with mucormycosis of paranasal sinuses with history of corona virus infections and having postive $\mathrm{KOH}$ fungal staining on nasal biopsy.

RESULT: 30 patients were studied.maxillary and ethmoid sinuses were most affected sinuses.eye involvement was seen in 83.3 percent cases while intracranial extension was seen in 13.3 percent.22 patients gives the history of steroid usage.comorbid condition Diabetes mellitus was being the most common.

CONCLUSION:The association between coronavirus and mucormycosis of paranasal sinuses must be given utmost importance.uncontrolled Diabetes and overuse of steroids are main factors.

\section{INTRODUCTION:}

Mucor is ubiquitous fungus present in our environment be it air, water., soil, decaying food and even as commensal in our nose. It is least potent organism to cause disease in itself and requires various prerequisite host factors to thrive. This group of fungus belong to class phycomycetes (zygomycetes) order Mucorales includes Rhizopus oryzae, mucor , Rhizomucor ,Cunninghamella, Saksenaea and Apophysomyces.(3) These fungi lifecycle comprises of spores and hyphae. Hyphae are ribbon like structure visible on microscopy on staining with specific stains and are diagnostic of fungal infection. The spores are like seeds for these species to multiply and reproduce.

Recent second wave of COVID had a disastrous consequences on health of indians and posed a tremendous load on Indian healthcare infrastructure. More than 2.5 crore Indians have been infected by SARS cov2 in the second wave and still there are more than 2.5 lakh active cases across the length and breadth of country. More than 3.15 lakhs people have succumbed to this illness with case fatality rate of $1.15 \%$. These numbers are humongous for any healthcare system over the world to tackle and thereby really stretched rather tore apart the healthcare system of India. Self prescription, quack prescription, blanket prescription on social media became prevalent during last month leading to overuse and misuse of certain prescription drugs. Adding to that we already are diabetic capital of world and poor socioeconomic condition making a large chunk of our population pre disposed to deadly angioinvasive mucor infection.(2) Mucormycosis infection of the sinuses is a life threatening invasive fungal sinusitis that typically affects immuno compromised individuals with an impaired neutrophilic response.(1) Other predisposition which led to the epidemic of mucormycosis is SARS cov 2 mutants which weakens immune system of body, misuse of broad spectrum antibiotics disturbing local commensal of nose, excessive steam inhalation causing mucociliary dysfunction and excessive intake of iron and zinc tablets which are substrate on which this fungus thrives. $(5,7)$ Nosocomial infection through ventilator tubings, oxygen tubings and excessive oxygen in itself can be a cause for mucormycosis surge.(9) Extensive use of steroids in COVID-19 in management can suppress immunity, opportunistic fungal infections to colonise. $(6,8)$ Hence, it is important to be aware that COVID 19 patients can develop fungal infection during late stage of the disease, especially ill patients.

\section{AIM:}

To study various predisposition for sudden upsurge in mucormycosis in second wave of COVID.

To study the pattern of involvement and spread of disease and to correlate clinicoradiologically.

\section{METHOD:}

A prospective observational study carried out in patients with rhino-orbital - cerebral mucormycosis post COVID presented in ENT department of Patna medical college and hospital,Patna,India over a period of two months from June to July 2021. All patients with invasive mucormycosis who presented to ENT department either as out-patient or in ENT causality or following departmental referral and who are recovered from coronavirus infection and positive $\mathrm{KOH}$ fungal staining on nasal biopsy.the biopsy material was collected in sterile container with normal saline and processed in department of microbiology.the direct demonstration of fungal filament in the clinical sample is essential in establishing diagnosis.Clinico -demographic profile, imaging findings, with special reference to diabetes (known and new diabetic) steroid usage (salt,dose and duration) were obtained.this data were recorded and analysed

\section{RESULTS:}

30 patients presented with rhino-orbital - cerebral mucormycosis were studied. 19 of these were male and 11 were Female ( table 2). 2 of these were corona positive at the time of presentation but had been infected for more than 14 days; rest had been infected earlier and had recovered.out of these 25 had orbital symptoms and sign when they presented to us. 6 of them had vision loss. (Figurel and tablel). Ethmoid and maxillary sinuses were most commonly involved sinuses .sphenoid and frontal involvement were less commonly involved( table 3). Middle turbinate and lateral wall of nose was involved in most cases. Palatal involvement was less 
common and seen 5 patients with classical black eschar on hard palate. Ptosis was the most common symptom which alarmed the patient however nasal crusting was the most common symptom which went unnoticed to patient. intracranial involvement seen in 4 patients.(table 4).Data regarding diabetes status of COVID associated mucormycosis (CAM)patient also gathered. 18 patients were known diabetic and 5 were newly diagnosed during the treatment. 3 patient had diabetic ketoacidosis. 24 patients gives the history of use steroids during treatment of coronavirus associated illness.other co morbidities apart from diabetes mellitus encountered in out patient were hypertension in $2, \mathrm{AKI}$ in 1 patient and 2 patients with lung involvement.there were 2 casualties during the period of study.(table 5)

\section{DISCUSSION:}

mucormycosis or zygomycosis also called phycomycosis initially described in 1885 by Paltauf, is an uncommon and aggressive fungal infection that usually affects patients with alteration of their immunological system.(11) It is a lethal fungal disease, with rhino orbital cerebral presentation being its most common form.(12) Although it has low incidence rate, varying from 0.005 to 1.7 per million population, many cases have been seen recently, amounting to significant increase in its incidence in the wake of ongoing coronaviruspandemic. Our observation revealed, middle aged (40-60years), male, rural, low middle class were most affected. More than $50 \%$ cases were found to be diabetic at the time of presentation of mucormycosis. Most of the subjects were diagnosed to have new onset of diabetes during or following course of COVID-19 illness.

\section{CONCLUSION:}

there is a trend of late presentation of patient to doctors at our centre when the disease has already spread. Most presented when ptosis and ophthalmoplegia already occurred leading to very poor prognosis,. Being a painless disease we must make an effort to disseminate the specific symptomatology of mucor and predisposed group, screening of all predisposed patients 2-3 weeks post covid should be made a norm in the state.Proper steps should be taken to prevent COVID associated mucormycosis(CAM) including judicial steroid usage for treatment of COVID-19 and control of blood sugar levels.

\section{Table 1. Age distribution}

\begin{tabular}{|l|l|}
\hline Age in years & Number of patients \\
\hline Less than 20 & 0 \\
\hline 20 to 40 & 8 \\
\hline 40 to 60 & 17 \\
\hline 60 to 80 & 5 \\
\hline
\end{tabular}

\section{Table 2. Sex distribution}

\begin{tabular}{|l|l|}
\hline Sex & Number of patients \\
\hline Male & 19 \\
\hline Female & 11 \\
\hline
\end{tabular}

Table 3.Incidence of paranasal sinus affected

\begin{tabular}{|l|l|}
\hline Sinuses affected & Cases \\
\hline Ethmoid & 27 \\
\hline Maxillary & 25 \\
\hline Sphenoid & 7 \\
\hline Frontal & 4 \\
\hline
\end{tabular}

Table 4. Spread of adjacent sites

\begin{tabular}{|l|l|}
\hline Adjacent spread & Number of patients \\
\hline Orbit & 25 \\
\hline Intracranial & 4 \\
\hline Palate & 5 \\
\hline
\end{tabular}

Table 5 associated. Comorbid condition

\begin{tabular}{|l|l|l|}
\hline Comorbidities & Status & Cases \\
\hline Diabetes mellitus (known) & Controlled & 10 \\
\hline & Uncontrolled & 5 \\
\hline Diabetes mellitus (new) & Controlled & 3 \\
\hline
\end{tabular}

|www.worldwidejournals.com |

\begin{tabular}{|l|l|l|}
\hline & Uncontrolled & 2 \\
\hline Diabetic ketoacidosis & & 3 \\
\hline Hypertension & Controlled & 1 \\
\hline Lungs & Pneumothax & 1 \\
\hline & Pleural effusion & 1 \\
\hline Kidney & Acute kidney injury & 1 \\
\hline
\end{tabular}

Table 6 type of steroid used by patient during COVID-19 treatment (few patients used multiple salts)

\begin{tabular}{|l|l|}
\hline Type of seroids & Number of patients \\
\hline Dexamethasone & 15 \\
\hline Methyleprednisolone & 5 \\
\hline Prednisolone & 2 \\
\hline
\end{tabular}

Table 7 duration of steroid used by patient during COVID-19 treatment

\begin{tabular}{|l|l|}
\hline Duration of use of steroid & Number of patients \\
\hline Less than 10days & 7 \\
\hline 10 to 20days & 10 \\
\hline More than 20days & 7 \\
\hline
\end{tabular}

Table 8 severity of COVID infection in patient with post COVID fungal infection.

\begin{tabular}{|l|l|l|l|}
\hline CT severity index & Number of patients & COVID type & Staging \\
\hline Less than 8 & 0 & Mild & - \\
\hline 8 to 15 & 12 & Moderate & $1,2,3$ \\
\hline 15 to 2 & 14 & Severe & 2,3 \\
\hline
\end{tabular}

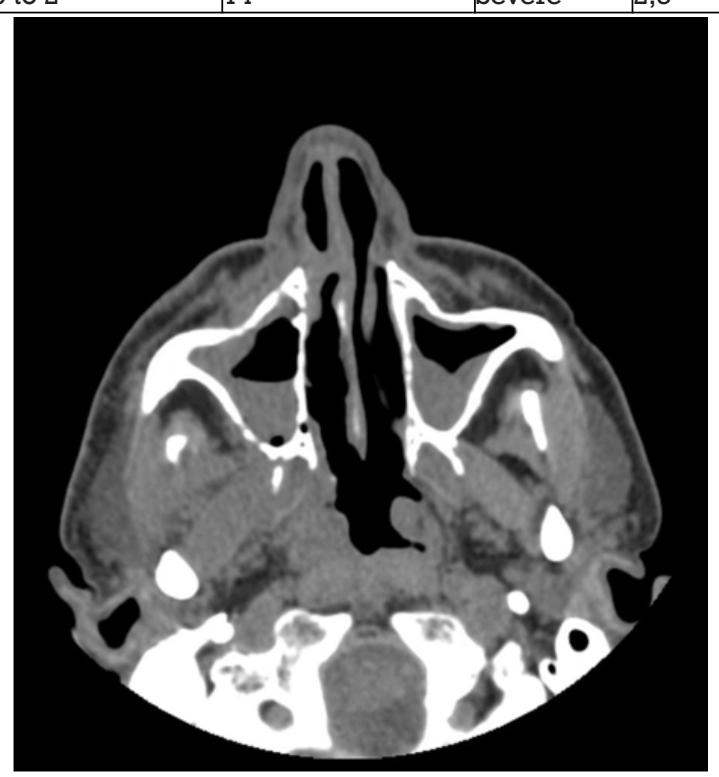

Axial NCCT PNS showing bilateral maxillary sinusitis.

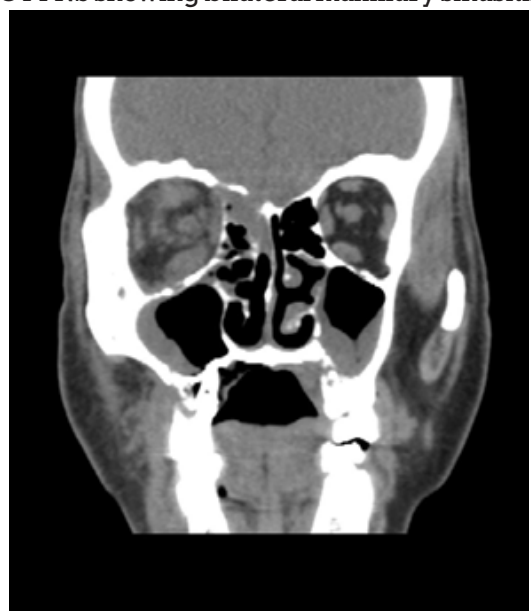

Coronal NCCT PNS showing pan sinusitis,erosion of cribriform plate,right orbit optic neuritis,inflammed extraocular muscles and fat 


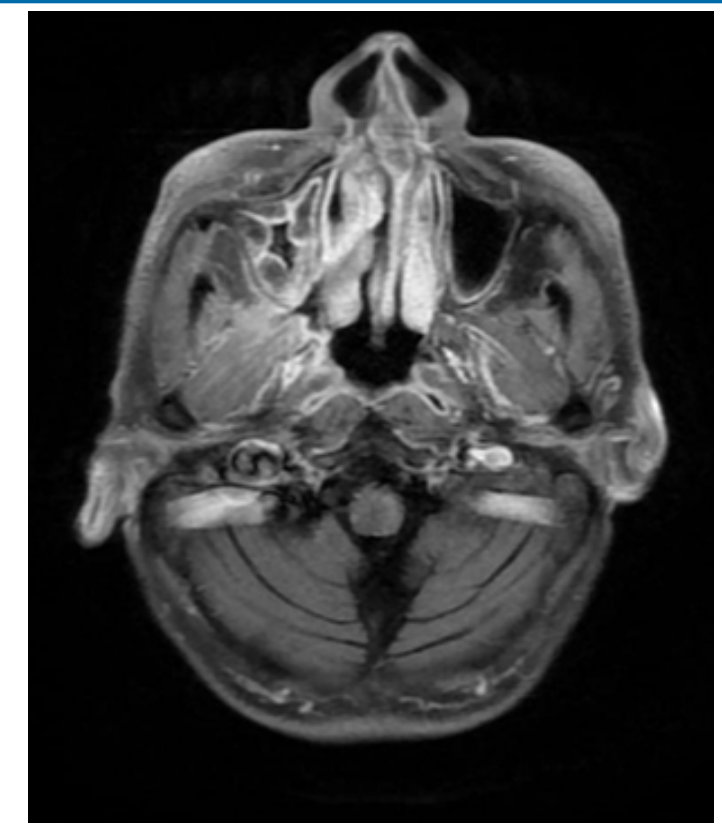

Tl post contrast axial images showing mucosal enhancement in maxillary sinus, infra temporal fossa on right side

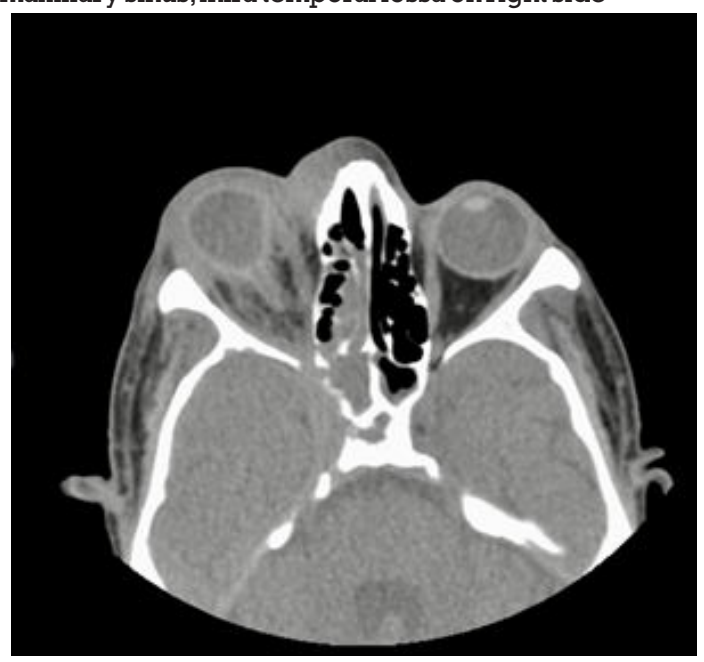

Axial NCCT scan showing right orbit intra and extraconal fat stranding with bulky medial and lateral rictus, thickened inflammed optic nerve

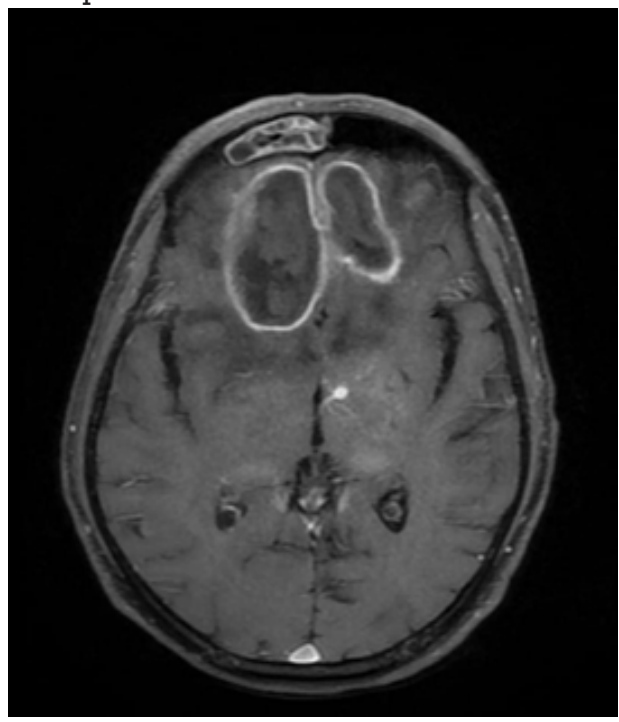

Axial Tl contrast images showing bifrontal abcess and frontal sinusitis

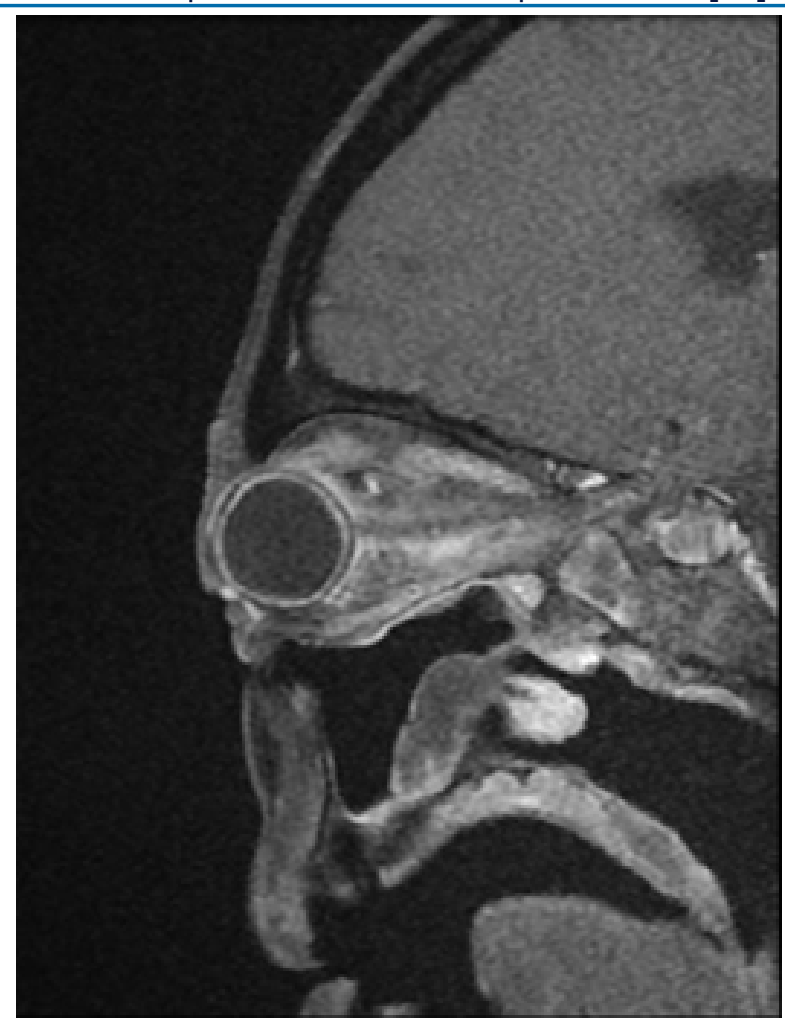

Sag Tl contrast images showing abnormal enhancement of extraocular muscles,optic nerve posterior sclera and intraocular and extraocular fat

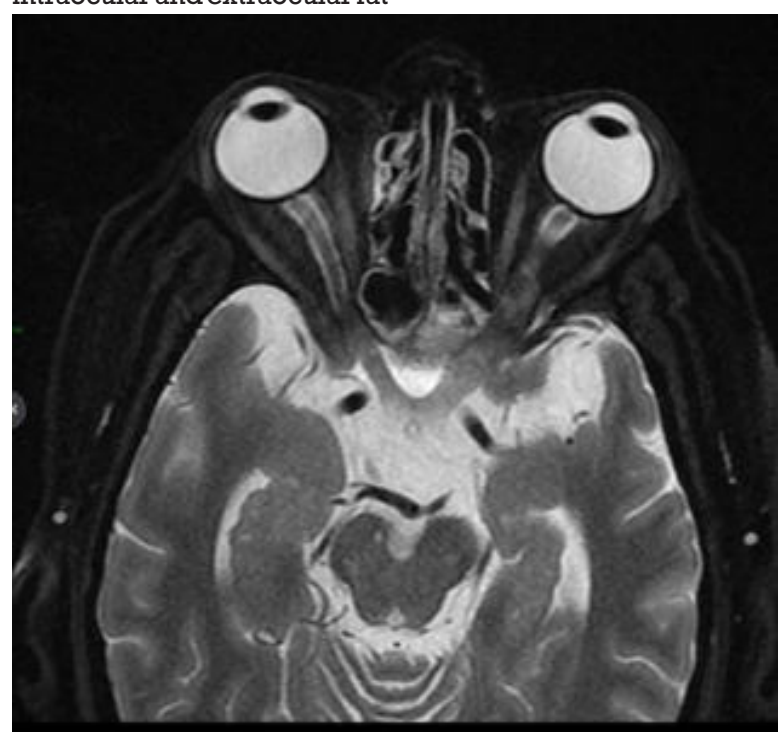

Axial T2 images showing bulky prechiasmatic part of left optic nerve

\section{REFERENCES}

1. Sharma S, Grover M, Bhargava S, Samdani S, Kataria T (2021) Post coronavirus disease mucormycosis: a deadly addition to the pandemic spectrum.J Largol Otol 8:1-6

2. John TM, Jacob CN, Kontoyiannis DP (2021) When uncontrolled diabetes mellitus and severe COVID-19 converge: the perfect storm for mucormycosis.J Fungi Basel Switzerland. 7(4):298

3. Singh AK, Singh R, Joshi SR, Misra A (2021) Mucormycosis in COVID-19:a systematic review of cases reported worldwide and in India

4. Mohindra S, Mohindra S, Gupta R, Bakshi J, Gupta SK. Rhinocerebral mucormycosis: the disease spectrum in 27 patients. Mycoses 2007:50:290-6

5. Mehta S, Pandey A. Rhino-orbital mucormycosis associated with COVID-19. Cureus2020;12:e10726.

6. Gillespie MB, O'Malley BW. An algorithmic approach to the diagnosis and management of invasive fungal rhinosinusitis in the immunocompromised patient. Otolaryngol Clin North Am 2000;33:323-34

7. Gupta S, Goyal R,Kaore NM. Rhino-orbital-cerebral mucormycosis: battle with the deadly enemy. Indian J Otolaryngol Head Neck Surg 2020 mar;72(1):104-11 
PARIPEX - INDIAN JOURNAL OF RESEARCH | Volume - 10 | Issue - 11 | November - 2021 | PRINT ISSN No. 2250 - 1991 | DOI : $10.36106 /$ paripex

8. Ahmadikia K, Hashemi SJ, Khodavaisy S, Getso MI, Alijani N, Badali H, et al.The double-edged sword of systemic corticosteroid therapy in viral pneu-monia: a case report and comparative review of influenza-associated mucormycosis versus COVID-19 associated mucormycosis. Mycoses 2021 Feb:13256. https:// doi.org/10.1111/myc

9. Elinav H, Zimhony O, Cohen MJ, Marcovich AL, Benenson S. Rhinocerebral mucormycosis in patients without predisposing medical conditions: a review of the literature. Clin Microbiol Infect 2009;15:693-7

10. Munir N, Jones NS. Rhinocerebral mucormycosis with orbital and intracranial extension: a case report and review of optimum management. J Laryngol Otol $2007 ; 121: 192-5$

11. Paltauf A. Mycosis mucorina. Vie how's Arch Pathol Anat Physiol Klin Med 1885;102:543-64

12. Arnáiz-García ME, Alonso-Peña D, González-Vela Mdel C, García-Palomo JD, Sanz-Giménez-Rico JR, Arnáiz-García AM. Cutaneous mucormycosis: report of five cases and review of the literature. J Plast Reconstr Aesthet Surg 2009;62:e434-41 